\title{
Health Promotion for Older People in Lithuania: Between bureaucratic and financial constraints
}

\author{
Milena Pavlova ${ }^{1}$, Liubove Murauskiené ${ }^{2}$, Elina Miteniece', \\ Agnieszka Sowa ${ }^{3}$, Iwona Kowalska-Bobko ${ }^{4}$, Alicja Domagała ${ }^{4}$, \\ Wim Groot ${ }^{5}$
}

\begin{abstract}
${ }^{1}$ Department of Health Services Research, CAPHRI, Maastricht University Medical Center, Faculty of Health, Medicine and Life Sciences, Maastricht University, Maastricht, the Netherlands; ${ }^{2}$ Institute of Public Health, Faculty of Medicine, Vilnius University, Vilnius, Lithuania; Public Enterprise "MTVC" ("Training, Research and Development Centre"), Verkiu, Vilnius, Lithuania; ${ }^{3}$ Department of Social Policy, Institute of Labour and Social Studies, Warsaw, Poland; ${ }^{4}$ Institute of Public Health, Faculty of Health Sciences, Jagiellonian University Medical College, Cracow, Poland; ${ }^{5}$ Department of Health Services Research, CAPHRI, Maastricht University Medical Center, Faculty of Health, Medicine and Life Sciences, Top Institute Evidence-Based Education Research (TIER), Maastricht University, Maastricht, the Netherlands
\end{abstract}

Address for correspondence: Milena Pavlova, Department of Health Services Research, Faculty of Health, Medicine and Life Sciences, Maastricht University, PO Box 616, 6200 MD Maastricht, the Netherlands, +31-43-3881705, m.pavlova@maastrichtuniversity.nl

\section{Authors contribution}

MP and EM designed the concept, MP carried out the data collection and analysis, and drafted the paper, LM, AS, IK and AD commented on the paper and provided additional data, EM and WG reviewed the draft and provided comments for the final version. All authors read and approved the final version submitted.

\section{Abstract}

The health system in Lithuania has a strong focus on hospital treatment. Overall, there is a lack of sufficient funds explicitly devoted to public health. This country report draws upon several national reports focused on the Lithuanian health system and other country-specific sources in order to outline the major institutional and financing challenges for health promotion in Lithuania, specifically for older adults. As suggested in our review, the key problems in public health services in Lithuania, including health promotion for older persons, are the bureaucratic and financial constraints, a lack of intersectoral cooperation, staff shortages and capacity problems. The implementations of public health initiatives greatly depend on the political will and the government's ability to implement policies, which are still weak in Lithuania. Moreover, the public health legislation lacks clarity and fails to provide an adequate base for local-level evidence-based interventions. Concrete action plans, as those recently developed in the area of healthy aging and health inequalities, are needed to provide guidance for health promotion among older adults.

Key words: public health, health promotion, older adults, health policy, Lithuania 


\section{Introduction}

The concept of public health first appeared in Lithuania in the 1990s. In 1991, the Supreme Council approved the National Health Concept of Lithuania, which outlined the need of public health reforms as well as a stronger focus on health promotion and disease prevention [1]. The document provided a starting point for the development of public health training programs as well as legislation and regulations related to public health activities in the country. This paper reviews key national reports focused on the Lithuanian health system and other country-specific sources in order to outline the major institutional and financing challenges for health promotion in Lithuania, specifically for health promotion focused on older adults. The paper has a policy orientation and provides an overview of the topic for decision-makers in Lithuania, as well as for those in other countries in the region who could learn from the Lithuanian experience.

\section{Legislation on public health and health promotion}

The principal guidelines for the provision of public health services in Lithuania were first outlined in the Health System Law of 1994. In this period, the Public Health Surveillance Service was also established within the Ministry of Health, which replaced the Soviet-era sanitary-epidemiological services. The concept of public health was also introduced in the Lithuanian Health Program of 1998, which covered the period 1998-2010. Based on this program, in 2002, the Public Health Law and the Public Health Monitoring Law were adopted by the Lithuanian Parliament and later also the National Public Health Strategy 2006-2013 [2-4].

Other laws and regulations that guide the public health sector activities in Lithuania include the Law on Consumer Protection (1994), the Law on Prevention and Prophylaxis of Communicable Diseases (1996), the Law on Alcohol Control (1995), the Law on Tobacco Control (1995), the Law on Product Safety (1999), the Law on Food (2000), the Law on Dangerous Substances Control (2001) and the Occupational Health and Safety Law (2003) $[3,4]$.

In 2011, the Lithuania's Health System Development Dimensions 2011-2020 was adopted, which stipulates the directions for the development of the Lithuanian health system. The main objective of this document is to consolidate the efforts of different health care stakeholders for the creation of more efficient and competitive health services. The key areas covered by this document are health improvements and self-responsibility for health, expansion of the health care market and creation of fair competition mechanisms, increasing transparency, cost-effectiveness and rational use of resources, as well as evidence-based care and access to safe and quality services. The Alcohol and Drug Control Program was also adopted in 2011 [4].
The legislative and regulative base of the public health activities in Lithuania continue to develop also at present. In the period 2012-2014, the Lithuanian government approved the National Progress Program for 2014-2020, the state progress strategy Lithuanian 2030, the Lithuania Health Strategy 2014-2025, as well as the horizontal inter-institutional action plan "Health for All" as part of the Lithuanian 2030 Strategy [4]. The improvement of population health is seen in the latter document as a horizontal priority, which is key for the achievement of the three vertical priorities, namely smart economy, smart society and smart governance [2]. In 2015, the new Public Health Development program for 2016-2023 was approved. The legislation implementation is outlined further on in this paper.

\section{Health system indicators}

Before 1990, Lithuania had a health care system organized according to the Semashko model like all other Soviet Union republics. The system was hierarchical and strongly centralized with regard to planning, funding and service provision. The health care reforms during the transition period, resulted in the creation of a decentralized insurance-based health system predominantly funded by the National Health Insurance Fund (NHIF) based on compulsory insurance contributions. However, there are also high out-of-pocket payments, which are a cause for concern as they threaten the access to health care for vulnerable groups $[3,5]$. With the decentralization of the health system in the 1990s, the provision of primary and social care, and public health activities at the local level became the responsibility of the municipalities. It was expected that the municipalities can better meet the needs of the communities. This became difficult to achieve in the recent years because public health spending was reduced as a result of the economic crisis [3]. In 2013, the total expenditure on preventive services was only $1.34 \%$ of the total expenditure on health (see Table I). Recently however, there were significant investments in the network of local health bureaus and central public health organizations.

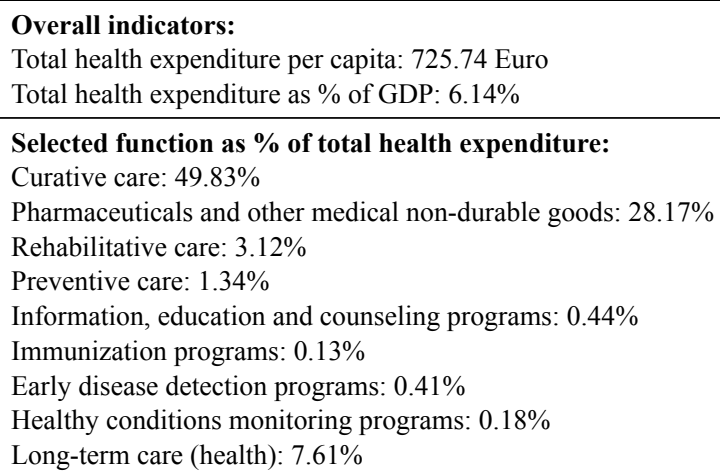

Selected function as \% of total health expenditure:

Curative care: $49.83 \%$

Pharmaceuticals and other medical non-durable goods: $28.17 \%$

Rehabilitative care: $3.12 \%$

Preventive care: $1.34 \%$

Information, education and counseling programs: $0.44 \%$

Immunization programs: $0.13 \%$

Early disease detection programs: $0.41 \%$

Healthy conditions monitoring programs: $0.18 \%$

Long-term care (health): $7.61 \%$

Table I. Health system indicators - Lithuania (data for 2013).

Source: Based on the Eurostat database. 


\section{Population aging indicators}

An important demographic feature in Lithuania, is the considerable gender gap in life expectancy at birth, which is the highest among the EU member states [3]. In 2013 , men were expected to live 68.5 years compared with 79.6 years for women (Table II). Besides, similar to most Central and Eastern European countries, a reduction in the population size was experienced in Lithuania due to the low fertility rate and substantial migration during the transition period as well as during the recent economic crisis [6]. At the same time, life expectancy has increased. The intensity of these demographic changes characterizes Lithuania as one of the fastest ageing countries in Europe [7]. Hence, there are concerns that the working-age population will decline dramatically in the coming years, which will bring a number of economic, labor market and social challenges, and could make it difficult to sustain the economic growth and improvements in living standards [6].

Life expectancy:

Life expectancy at birth: 74.7 years

Life expectancy at birth males/females: 69.2/80.1

Life expectancy at 65: 17.4 years

Life expectancy at 65 males/females: $14.3 / 19.5$

Healthy life years:

Healthy life years at 65 males: 6.1 years

Healthy life years at 65 females: 6.1 years

Share of older population:

Proportion of population aged $65+: 18.7 \%$ of total population

Proportion of population aged $80+: 5.1 \%$ of total population

Old age dependency ratio $65+: 28.1 \%$

Table II. Population ageing indicators - Lithuania (data for 2014/2015)

Source: Based on own review of literature.

\section{Health status of older population}

Like most Central and Eastern European countries, Lithuania scores below EU average on most of the main health indicators. Most importantly, over the past decades, mortality due to preventable causes, such as unhealthy lifestyle, was higher in Lithuania than in Western European countries [8]. Important concerns are the risk factors such as smoking, overweight and obesity, unhealthy nutrition habits, as well as physical inactivity [9]. To a great extent, this is attributed to the lack of inter-sectoral public health interventions, particularly in relation to public health and lifestyle changes [3]. Such unhealthy lifestyle trends are observed among older adults as well. Gender differences related to the health status of older persons in Lithuania, are also found. In particular, long-standing illnesses and limitations in usual activities due to health problems, are more prevalent among older women than among older men (Table III). These gender differences, to a certain extent, are attributable to the worse social position for elderly women as a result of lower level of socialization, education and social networks
[10], and also to their longer life expectancy. Prevalent mental health problems among elderly include: anxiety, sleeping and eating disorders, depression, mania, Dementia (Alzheimer and Pick disease). An increased level of suicides among elderly is observed.

\section{Prevalence of long-standing illness: \\ Age group 65-74 males/females: 58.4\%/64.7\% \\ Age group 75-84 males/females: $71.1 \% / 81.5 \%$ \\ Age group $85+$ males/females: $89.0 \% / 89.9 \%$}

Self-perceived long-standing limitations in usual activities due to health problems:

Age group 65-74 males/females: $49.2 \% / 57.3 \%$

Age group 75-84 males/females: $64.2 \% / 77.1 \%$

Age group $85+$ males/females: $83.0 \% / 87.1 \%$

Table III. Health status of older population - Lithuania (data for 2014).

Source: Based on the Eurostat and EU-SILC databases.

\section{Potential sources of funding public health and health promotion activities}

The health system in Lithuania has historically focused on hospital services and hospital treatment [4]. Overall, there is a lack of sufficient funding explicitly devoted to public health, which is also indicated by the low overall spending on preventive care compared with the spending on curative care, pharmaceuticals and other medical non-durable goods (see Table IV). Potential sources of funding for public health activities, including health promotion activities, comprise: state and municipalities' budgets; the NHIF budget, EU funds and other international funds, the health promoters' own funds, and other funding sources [4].

The funding of public health institutions is the responsibility of either the government or the municipality. National public health institutions, such as specialized public health institutions of the Ministry of Health, as well as the State Food and Veterinary Service, the State Labor Inspectorate, and the Drug, Tobacco and Alcohol Control Department, are financed through the state budget. Municipal public health bureaus are financed by both budgets allocated by the Ministry of Health and local budgets [4]. The Ministry of Defense and the Ministry of Interior in Lithuania also run health facilities.

Public health services provided by health care providers are financed through the NHIF budget, which comprises the citizens' compulsory insurance contributions and additional budget allocations by the Ministry of Finance to the Ministry of Health (as contributions for those insured by the state and as subsidies to cover the treatment of those no insured). At the primary health system level, some basic public health functions, such as health promotion, primary prevention and immunization, are carried out by GPs who are reimbursed by the NHIF. Also, GPs, medical specialists and dentists are involved in the service provision within the national screening programs financed by the NHIF. Among other things, 


\begin{tabular}{|c|c|c|}
\hline Source of funding & Beneficiary & Additional Comments \\
\hline $\begin{array}{l}\text { Taxes } \\
\text { Including } \\
\text { - general taxes }\end{array}$ & $\begin{array}{l}\text { The general public or specific target group who } \\
\text { use services provided by state public health } \\
\text { institutions or municipal public health bureaus. }\end{array}$ & $\begin{array}{l}\text { The general tax revenue allocated to public health } \\
\text { is channeled form the Ministry of Finance to the } \\
\text { Ministry of Health, and then used or redistributed } \\
\text { by the Ministry of Health for public health services } \\
\text { provision. }\end{array}$ \\
\hline $\begin{array}{l}\text { Health insurance premiums } \\
\text { Including } \\
\text { - social insurance } \\
\text { - private insurance }\end{array}$ & $\begin{array}{l}\text { Socially insured patients who use public health } \\
\text { services provided by the NHIF. }\end{array}$ & $\begin{array}{l}\text { Compulsory insurance premiums for the NHIF, } \\
\text { which also cover some basic public health services } \\
\text { provided by GPs, specialists or dentists. } \\
\text { No role in public health for private insurance. }\end{array}$ \\
\hline Other public institutions & $\begin{array}{l}\text { Beneficiaries of public health services provided by } \\
\text { other ministries. }\end{array}$ & $\begin{array}{l}\text { e.g. the Ministry of Justice and the Ministry of } \\
\text { Interior. }\end{array}$ \\
\hline \multicolumn{3}{|l|}{ Other sources } \\
\hline Funds from the employers & Employees. & Company projects or initiatives. \\
\hline Households & $\begin{array}{l}\text { Users of public health services covered by the } \\
\text { NHIF or at the private sector. }\end{array}$ & $\begin{array}{l}\text { Co-payments for some services under the NHIF or } \\
\text { full fees in the private sector. }\end{array}$ \\
\hline Foreign & $\begin{array}{l}\text { International research projects and EU funds } \\
\text { beneficiaries. }\end{array}$ & $\begin{array}{l}\text { International research projects and programs } \\
\text { funded by through the EU structural funds. }\end{array}$ \\
\hline Others & Patients with chronic diseases. & $\begin{array}{l}\text { Provided by NGOs and associations of patients } \\
\text { with chronic diseases. }\end{array}$ \\
\hline
\end{tabular}

Table IV. Sources of public health funding in Lithuania.

Source: Based on own review of literature.

NHIF covers the provision of information on the issues of disease prophylaxis, and preventive health check-ups of persons eligible for the compulsory health insurance, as prescribed by the Ministry of Health [11].

There are also user charges for services provided under the NHIF, including public health and health promotion services (e.g. check-ups). There is no exemption for older persons from such charges. A small charge is required to register with a GP but if a patient chooses to change physician within six months after registration, there is a further administrative charge [11]. However, there are also quasi-formal (unregulated) charges set by the different providers as well as payments for services not included in the list of personal health care services financed by the NHIF [12].

The Ministry of Economy and Ministry of Finance also participate in decisions about investments in the health sector, including investments in the area of public health. Such investments can take place within the state investment programs or programs funded from the EU structural funds [4]. Thus, a substantial part of the public health interventions is carried out through national and international programs, as well as international projects. For example, substantial funding has been obtained for strengthening the capacities of the Lithuanian public health system to meet the standards of the EU regulations [4]. In 2013, there were about 50 projects in the field of public health, financed from the EU structural funds or other international funding mechanisms (the EU Health Program, WHO). These projects focused on the development of health impact assessment, professional training, communicable disease prevention, monitoring injuries, reducing health inequalities, strengthening pre- paredness for emergencies, improving radiation protection, expanding public health laboratory functions and improving mental health [3].

Nongovernmental organizations (NGOs) and associations of patients with chronic diseases are also active in the health promotion area but mostly in discussions, lobbying and dissemination of information [4]. There is a recent program for funding NGOs. Since 2016, NGOs are competing for grants from the State Health Strengthening Fund. Major priorities are prevention of alcohol consumption, mental health improvements and healthy lifestyle.

Private health insurance is not well developed in Lithuania. Such insurance mostly covers risks during a travel and stay abroad, as well as premium payments and payouts. No public health or health promotion activities are mentioned in the private health insurance packages offered.

\section{Institutional analysis (sectors, organizations and their functions)}

The main responsibility for the regulation and supervision of the health system in Lithuania, including public health activities such as health promotion and primary prevention, lies with the Ministry of Health. The ministry develops health policies and national health programs, coordinates the implementation of these policies and programs, and monitors the implementation outcomes. It also drafts legal acts and issues regulations related to the health sector. Moreover, the Ministry of Health and national public health agencies (e.g. Heath Education 
and Diseases Prevention Centre) provide manuals and guidelines as well as training for professionals based on current empirical evidences. The Ministry of Health also runs 15 health care facilities and national public health institutions, and develops health care infrastructure. Major investments in the health sector are joint decisions of the Ministry of Health and the Ministry of Finance [4].

Due to recent reforms, there is a National Public Health Center with 10 regional departments subordinated to the Ministry of Health, which together with the Radiation Protection Center and the Health Emergencies Situations Center are responsible for public health safety, dealing with health emergencies, consumer rights protection, environmental safety, as well as prevention and control of communicable diseases.

There are also several public health bodies which function under the Ministry of Health, such as the Centre for Health Education and Disease Prevention, the Institute of Hygiene, the State Mental Health Centre, the National Public Health Surveillance Laboratory, Forensic agencies, Addiction Diseases Centers, and the Centre for Communicable Diseases and AIDS. Specifically, the Centre for Health Education and Disease Prevention carries out interventions in the area of non-communicable diseases and injury prevention, health promotion, physical activity and nutrition, environmental health and health specialist training. The interventions carried out by the Institute of Hygiene relate to the monitoring of population health and its determinants, measuring health inequalities and work environmental effect on health, health technology assessment in public health and occupational health, developing and testing innovative interventions in public health. The State Mental Health Centre implements mental health policy and public mental health measures to monitor and strengthen the population mental health $[3,4]$.

In addition, the National Health Board, which is subordinate to the Parliament, plays an important role in health policy implementation. The members of the board represent the municipalities, universities, NGOs and public health professionals. They coordinate the public health policy implementation carried out by the municipalities at the local level [4]. Furthermore, the Drug, Tobacco and Alcohol Control Department, which reports to the government, is the main institution responsible for tobacco and alcohol control.

Municipalities are responsible for setting up and implementing local health programs and public health activities. For this purpose, the municipalities have established Public Health Bureaus, which offer health promotion, public health monitoring, communicable disease prevention, prevention of non-communicable diseases and injuries, implementation and evaluation of public health programs [13]. At present, there are 45 bureaus in the country. Municipalities that do not have such bureaus, purchase public health services from other municipalities. The activities of a municipal public health bureau are monitored by the municipality board and the municipal director of administration. The board approves the health activity programs and sets their budget, and the director of administration monitors the implementation of the programs $[3,4]$.

The NHIF coordinates, supervises and audits the activities of the territorial health insurance branches, including the budget planning and control, and other financial decisions. The territorial health insurance branches are responsible for signing contracts with health care providers and pharmacies, reimbursing these providers, disseminating information about health insurance provisions, controlling the local service provision and financing municipal public health programs. The territorial health insurance branches have supervisory boards consisting of representatives from the Ministry of Health, the NHIF and the municipalities [4]. Screening programs including screening programs for disease prevention (such as cardiovascular disease prevention targeting population 40-55 year old males and 50-65 year old females) are funded through the NHIF.

Other stakeholders in the Lithuanian public health sector include voluntary organizations (NGOs such as the Red Cross Society and the Caritas Federation) and associations of patients with chronic diseases (the Diabetes Association, the Association of the Blind, the National Tobacco and Alcohol Control Coalition, the Lithuanian Heart Association). They are involved in the public debates and some of them are active in providing assistance, disseminating information and promoting proper treatment and prevention, as well as lobbying the interests of certain patient groups [4]. The Diabetes Association provides assistance to diabetic patients, promotes the study, the spread of knowledge and the proper treatment of diabetes, attempts to remove limitations of diabetics discrimination related to labor, studies and insurance. The Lithuanian Heart Association helps those who are suffering from heart disease, and those who want to avoid it, and it assists in improving physicians' professional skills related to heart diseases [4]. These stakeholders communicate with the state public health institutions described above, at both national and regional/municipal level.

\section{HPAOP - Health Promotion for Older People (examples of good practices)}

In Lithuania, there are various nationwide programs that have a direct or indirect relation to health promotion and prevention among people aged 50+. These programs are implemented by applying a complex approach contributing to solving the age-related problems [14]. However, direct financial-incentive programs related to health promotion that target the group of elderly are absent. Some activities in the field of "active aging" could be found in the frame of international projects. Overall, these activities are relatively few, scattered and lack sustainability.

The following cases describe good practice programs and projects in Lithuania that have a relation to the maintenance of the health and social activities of older persons: 
- The National Screening Programs financed by the NHIF. Women up to 60 years are offered cervical cancer screening every three years, and those aged 50-69 years are offered breast cancer screening every two years. Men aged 50-75 years (and over 45 for those at risk) are eligible for prostate cancer checks every two years. In addition, biannual colorectal cancer screening is available for adults aged $50-75$ years; annual screening for those with high cardiovascular risk is available to men aged $40-55$ years and women aged 50-65 years [4].

- The National Anti-Discrimination Programs. These programs aim to foster the respect for human beings, including elderly persons, to support the implementation of the principle of non-discrimination and equal opportunities within the Lithuanian legislation, to raise social awareness and understanding of tolerance based on age, gender, race, nationality, language, origin, social status, religion, convictions or beliefs, sexual orientation, disability etc. The programs provide a platform for organizing various educational events and NGO supportive activities aimed at reducing discrimination. The initiatives of the Office of the Equal Opportunities Ombudsperson are some examples of such programs [14]. These programs can be especially beneficial for the elderly population because discrimination based on age (including the discrimination of elderly patients within the health system) has been observed in the country [7].

- Cross-border initiatives to support the employability of older people. These initiatives are funded by the European Social Fund. Examples of such initiatives in Lithuania are the EQUAL Network "Elderly $45+$ " and Older Workers Learning Net. The EQUAL Network "Elderly 45+", among other things, offers a toolbox "Ageing in the Professional Life", which includes instruments against age discrimination and promotion of the employment of older workers. This toolbox is designed with the participation of various European countries, including Lithuania. In addition, the Older Workers Learning Net includes educational institutions from Lithuania and other EU member states that cooperate in the development of e-learning programs for older workers. These e-learning programs are developed by taking into account the individual learning pace and living habits of the elderly individuals. Another goal of the network is to promote the benefit from business training of older workers among the employers [15].

- Being Healthy and Fit in Later Life (HEFILL) was a Grundtvig Learning Partnership Project provided by two seniors citizens associations from Lithuania and Austria, and two sport associations from Germany and Italy (2010-2012). This project aimed to: exchange experience and good practice in the field of sports and physical activities in the later life and to make proposals on how to increase the level of physical activity among inactive older people. The qualified trainers and adult learners attended workshops, where services, activities and exercises targeting seniors, were demonstrated. These physical activities and exercises were filmed and will be made available in a DVD format for further implementation into practice in project's countries [16].

- From Isolation to Inclusion (i2i-project) was an international project focused on the identification and improvement of measures that enable population groups at a multi-dimensional risk of social exclusion, to actively and fully participate in the community life. The project was implemented in cooperation between local authority and external experts. The target group was older people at the risk of isolation and poverty, with disabilities or chronic disease. The project aim was to strengthen initiatives by older people for older people and establish the supporting networks for these initiatives. The aim was also to facilitate and encourage social and political changes focused on the improvement of the life conditions of the target group [17].

- Cultural and artistic projects for older persons. The Lithuanian government provides annual funding for cultural and artistic projects, which aim to encourage the citizens, including elderly people, to participate in creative activities and cultural initiatives. As a result, many elderly are members of cultural institutions, such as cultural centers that offer amateur artistic activities, as well as public libraries that promote public access. There are also public libraries for disabled and elderly people supported at home. These libraries bring prints by bus to the homes of such persons, and set up out-patient items in remote rural areas, disabled communities, and society centers. To a certain extent, these projects help older people in dealing with social exclusion, employment, education and lifelong learning issues and enable them to foster their social connections [18].

\section{National health promotion policy generally and addressed at the older people}

As mentioned earlier, the concept of public health appeared in Lithuanian policy documents only in the 1990's. The Lithuanian Health Program was launched in 1998 and the Law on Public Health was adopted in 2002. This law is the key policy document that defines the public health principles in the country as well as the overall approach to the implementation of these principles. However, the law is criticized for its lack of clarity on how health-related lifestyle interventions have to be designed and delivered, and how to collaborate with other sectors in such interventions. In the terms of this law, the health sector is solely responsible for the poor population health. The amendments in the law in 2007 defined the public health functions at national and local levels, and provided a legal base for municipalities to establish the Public Health Bureaus [3]. In addition, the State Program for Developing Public Health Care at Local Level (2007-2010) made it possible to develop the services of these bureaus. Evidence suggests that the public health 
bureaus have been effective in providing timely information about the population health status and increasing health awareness of the population [3].

In addition to the decentralization of public health service provision, a shift in the government health policy is also observed. While before the policy focus was on improving service quality and efficiency within the health care organizations, currently, the government emphasizes the issue of accessibility to health care and the role of public health in health policy. It is expected that by strengthening primary care, including public health services, more disease can be prevented and more patients can be treated at the primary level, which can help to increase the overall efficiency of the health system. However, the government has not yet undertaken any structural reforms in the health sector to realize this ambition [19]. Furthermore, the public health programs that are currently offered at the primary care level (such as screening programs), are opportunistic rather than population based even though they are describes as efficient $[3,20]$.

The lack of political will and the inability to implement policies can explain to a certain extent why Lithuania compares poorly with its neighbors in terms of health policy performance despite its well-trained public health workforce [21]. Also, a lack of institutional capacity in relation to the volume of responsibilities in the public health area has been observed. This problem has been partly resolved by the creation of the municipal public health bureaus, which have the responsibility to provide public health services to municipality residents [4].

One positive aspect of the municipal public health bureaus is their broad mission, goals and priorities to promote not only health but in general also the wellbeing of the community. They rely on local experience, community consultations and evaluations in planning their activities. This facilitates a partnership between the local governments, service providers, other stakeholders and the local community in the implementation of public health services and programs $[3,22]$. However, the municipal public health bureaus face various challenges such as the lack of public health specialists, shortage of funds and lack of regulations on the cooperation between medical and public health specialists [3].

In 2009, the Lithuanian government approved the National Strategy for Health and Safety at Work (20092012) and the action plan for its implementation. The Ministry for Social Security and Labor, the Ministry of Health, the Ministry of Education and Science, and the Ministry of Agriculture collaborate in the implementation process. This collaboration extends to research institutions, universities, trade unions, associations, enterprises, organizations, and employers' organizations. Importantly, the strategy prioritizes the need of strengthening the occupational health and safety policy through the development of trainings, dissemination of information and economic incentives. This priority corresponds to the EU requirement for progressive and constructive regulatory framework [15]. The strategy also emphasizes the need to improve the education systems and information con- cerning health and safety for employers and employees, fostering the health prevention services for employees, improving the safety of workers who perform hazardous activities, e.g. through training projects. The strategy also recognizes that depression caused by health problems may lead to the incapacity to work. Therefore, the promotion of mental health in the workplace is an important policy objective [15].

The social and economic consequences of population aging are also national priorities in Lithuania. The main policy document in this area is the National Strategy of Overcoming the Consequences of Ageing, which promotes the principles of active ageing. It creates the conditions to maximize older people's quality of life, recognize their experience and skills and adequately ensure their future [14]. The document is praised for its holistic approach towards population ageing and for encompassing various aspects, such as the demographic situation, income and income guarantees for older people, employment, health and social services, opportunities for promoting well-being of older people, access to cultural life, transport facilities, personal security, participation in the activities of non-governmental organizations and promotion of a positive image of ageing [14]. The focus is on the implementation of cross-sectoral strategies and programs to address the population ageing issues. Various policy documents have emerged as a result of this focus: the National Demographic (Population) Policy Strategy, the National Anti-Discrimination Programs, the National Program on Equal Opportunities for Women and Men, the Programs for Reduction of Regional, Social and Economic Disparities, and the Rural Development Strategy for 2007-2013.

In 2014, the Action Plan for Healthy Ageing Protection in Lithuania 2014-2023 was approved by a ministerial order. This action plan aims to encourage older persons to take care of their health. The plan focuses not only on the prevention of the most prevalent health problems, such as cardiovascular disease, stroke, and diabetes, but also on the promotion of a healthy life-style, for example, physical activity. One shortcoming of this plan is that the group of older people is not explicitly defined, which brings questions about its implementation [4].

Another action plan approved by a ministerial order in 2014, is the Action Plan for Reducing Health Inequalities in Lithuania 2014-2023. This plan focuses of the socio-economic dimension of health. It aims to reduce the heath inequalities in certain Lithuanian regions and among different social groups, including older persons. It also covers actions related to inequalities in access to health care, disease prevention, and health promotion programs [4].

\section{Conclusions and recommendations}

The Lithuanian government has recognized the importance of public health and has placed a priority on this area. However, there are still many obstacles to be removed before the positive health effects of this new health policy orientation can be observed. 
The key problems in public health services in Lithuania, including health promotion for older persons, relate to bureaucratic and financial constraints, lack of intersectoral cooperation, staffing problems and qualifications of the personnel responsible for implementing public health functions. The establishment, funding and activities of local public health greatly depend on the government's will and ability to implement public health policy, which are still week in Lithuania [3, 21]. According to the recent literature [23], there are certain failures in the functioning of the health care system in Lithuania. This is due to the absence of new national public health strategy as well as due to shortcomings on the local level [23]. Moreover, the public health legislation lacks clarity and fails to provide an adequate base for local-level evidence-based interventions. The assessment of local needs and the allocation of resources to public health measures depend on the knowledge and capacity of the municipalities. In Lithuania, a lack of institutional capacity in the area of responsibilities has been recognized at the local level. Concrete action plans, as those recently developed in the area of healthy aging and health inequalities, are needed to provide guidance on the public health policy implementation.

Overall, medical, cultural and social services for older people, as well as health promotion services, are underdeveloped in Lithuania and require the government's attention. Adequate access to such services is important for maintaining the health and well-being of older persons, and for providing them with an opportunity for an independent living [14].

There is also a need of a more comprehensive approach to the development of public health programs, and specifically in the area of health promotion. In particular, the focus should be on the evaluation of health promotion programs and the integration of this evidence in the development of subsequent programs. The evaluation should not only cover the program outcomes but also the implementation process to better understand how health promotion interventions can be best implemented in Lithuania. This also applies to future health promotion programs for older persons. Currently, there are only few good practices described in the public health area. Overall, multi-disciplinary research on primary prevention or health promotion is lacking. Cooperation between the health and non-health sectors is also absent [4]. Generation of empirical evidence on public health interventions and their dissemination among stakeholders that are directly or indirectly related to the public health sector, seem imperative for the improvement of population health in Lithuania.

\section{References}

1. Adany R., Villerusa A., Bislimovska J., Kulzhanov M., Public health education in Central and Eastern Europe, and Central Asia, "Public Health Reviews" 2011; 33: 105-133.

2. OECD, Lithuania: fostering open and inclusive policy making, OECD Publishing, Paris 2015, http://www.oecd. org/countries/lithuania/lithuania-fostering-open-and-inclu- sive-policy-making-9789264235762-en.htm; accessed: 19.10.2016.

3. Murauskiene L., Janoniene R., Veniute M., van Ginneken E., Karanikolos M., Lithuania: health system review, "Health Systems in Transition" 2013; 15 (2): 1-150.

4. Ministry of Health, Lithuania Country Review. JA-CHRODIS - Good Practice in the Field of Health Promotion and Primary Prevention, 2014, http://www.chrodis.eu/wp-content/uploads/2014/10/JA-CHRODIS_Lithuania-countryreview-in-the-field-of-health-promtion-and-primary-prevention.pdf; accessed: 19.10.2016.

5. Tambor M., Pavlova M., Rechel B., Golinowska S., Sowada C., Groot W., The inability to pay for health services in Central and Eastern Europe: evidence from six countries, "European Journal of Public Health" 2013; 24 (3): 378-385.

6. Bouman R., Horne R., Milasi S., Prasad N., Ageing and labour market implications for Lithuania, ILO Research Department working paper no. 6, International Labour Office, Geneva 2015, http://www.ilo.org/global/research/publications/WCMS_424066/lang--en/index.htm; accessed: 19.10.2016.

7. Selli K., Czabanowska K., Danusevičienė L., Butkevičienė R., Jurkuvienė R., Overall J., Discrimination of elderly patients in the health care system of Lithuania, "South Eastern European Journal of Public Health" 2016, VI; doi: 10.4119/ UNBI/SEEJPH-2016-124.

8. Tamosiunas A., Klumbiene J., Petkeviciene J., Radisauskas R., Vikhireva O., Luksiene D., Virviciute D., Trends in major risk factors and mortality from main non-communicable diseases in Lithuania, 1985-2013, "BMC Public Health" 2016; 16: 717.

9. Tamosiunas A., Luksiene D., Baceviciene M., Bernotiene G., Radisauskas R., Malinauskiene V., Bobak M., Health factors and risk of all-cause, cardiovascular, and coronary heart disease mortality: findings from the MONICA and HAPIEE studies in Lithuania, "PLoS ONE" 2014; 9 (12): e114283.

10. Stanojević Jerković O., Sauliūnẻ S., Šumskas L., Birt C., Kersnik J., Determinants of self-rated health in elderly populations in urban areas in Slovenia, Lithuania and UK: findings of the EURO-URHIS 2 survey, "European Journal of Public Health" 2015; doi: 10.1093/eurpub/ckv097.

11. Republic of Lithuania, Law on Health Insurance (as last amended on 10 July 2014 - No XII-1001) 1996, http://www. vlk.lt/sites/en/legislation/national-legislation/Documents/ EN\%20SDI\%20aktuali\%202014-07-10.pdf; accessed: 19.10.2016.

12. Stepurko T., Pavlova M., Gryga I., Murauskiene L., Groot W., Informal payments for health care services: The case of Lithuania, Poland and Ukraine, "Journal of Eurasian Studies" 2015; 6 (1): 46-58.

13. Kavaliunas A., Sceponavicius A., Asokliene L., Developing public health at local level: Lithuanian example, in: Kavaliunas A. (ed.), IFEH 12th World Congress on Environmental Health: new technologies, healthy human being and environment, Medimond International Proceedings, Bologna 2012: 1-6.

14. Ministry of Social Security and Labor, Report on the follow-up to the Regional Implementation Strategy (RIS) 
of the Madrid International Plan of Action on Ageing (MIPAA) in Lithuania, 2012, http://www.unece.org/filead$\mathrm{min} / \mathrm{DAM} / \mathrm{pau} /$ age/country_rpts/LTU_report.pdf; accessed: 19.10.2016.

15. Newiger-Bogumil C., Creative age management strategies for SMEs in the Baltic Sea Region. Annex 1: Country Studies: Lithuania, 2012, http://www.best-agers-project.eu/ Portals/18/Activities/Lithuania_Country\%20Study.pdf; accessed: 19.10.2016.

16. HeFiLL, HeFiLL - Healthy and Fit in Later Life, 2013, http://www.generationen.at/hefill-healthy-and-fit-in-laterlife.phtml; accessed: 19.10.2016.

17. i2i Project, From isolation to inclusion, 2007, www.i2iproject.net; accessed: 19.10.2016.

18. Mažionienė A., Valeckienė D., Mažionytė I., Beržinytė D., Aleksandravičiutė T., Bliudžiutė D., Razmute R., Zakarauskaite K., Ageing in Lithuania, 2011, http://www. mep_activeageing.ipleiria.pt/files/2012/01/Klaipeda-StateCollege1.pdf; accessed: 19.10.2016.

19. Nakrosis V., Vilpisauskas R., Jahn D., Sustainable governance indicators: 2015 Lithuania report, Bertelsmann Stiftung, Gütersloh 2015.
20. Momkuviene V., Independent experts positively evaluate prevention programmes' efficiency, National Health Insurance Fund, Vilnius 2011, http://www.vlk.lt/vlk/ $\mathrm{pr} /$ ?page $=$ item $\&$ kat_id $=1 \&$ date $=2011-07-20 \&$ item id=1910; accessed: 19.10.2016.

21. McKee M., Mackenbach J., Conditions for successful health policies, in: Mackenbach J., McKee M. (eds), Successes and failures of health policy in Europe: four decades of divergent trends and converging challenges, Open University Press, Maidenhead 2013: 331-355.

22. Kalediene R. et al., Public health bureaus: new players in health improvement in Lithuania, "Acta Medica Lituanica" 2011; 18: 183-189.

23. National Audit Office of Lithuania. Organising public health improvement in municipalities. Public Audit Report No. VA-P-10-2-3, National Audit Office of Lithuania, Vilnius 2015. 